\title{
Influence of Digital Computer Technology on Architectural Design Teaching Mode
}

\author{
Huang Ting $^{1}$ and Jiang Sicheng ${ }^{2}$ \\ ${ }^{1}$ Department of Architecture, College of Civil Engineering, Yancheng Institute of Technology, \\ Yancheng, 224000 \\ ${ }^{2}$ Yancheng Architectural Design Research Institute Co., Ltd., Yancheng, 224000
}

\begin{abstract}
This paper starts from the influence of CAAD system on different stages of architectural design and describes the application of digital technology in architectural design based on the development status of architectural design; meanwhile analyzes the teaching status of domestic computer aided architectural design curriculum and existing problems; and discusses its influence on architectural design field and even the educational pattern of architectural design major in combination with new features of the development of the current construction industry and computer aided architectural design technology.The emphasis lies in proposing constructive instructions for the reform of educational pattern of architectural design major in China.
\end{abstract}

Keywords: digital technology, computer aided architectural design, architectural design, teaching mode.

\section{Introduction}

No digital computer technology in any era has such strong impact on architectural design, architectural teaching and practice. "Image architecture, digital simulation and virtual scene" etc. have gradually become "progressive" architectural design nouns. Ranging from computer aided drawing (CAD) to computer aided architectural design (CAAD), architecture has changed in the reform of design means, tools and medium. We can be more clear about how architectural design teaching mode should adapt to such reform by analyzing the influence of digital computer technology on architectural design. The change of design object results in the change of the role of architect and the teaching orientation of architecture major. New architecture and even new architect emerge at the right moment.

\section{Application of Digital Technology in Architectural Design and Its Influence on Design Thinking}

\subsection{Application of Digital Technology in Architectural Design}

The application of digital computer technology in architectural design not only involves drawing, model, animation, network and free form, but also reaches various 
fields in the process of architectural construction such as building construction, structural design and environmental index design.

Architect Frank Gehry used French aviation industrial manufacturing aircraft computer software "CATIA" system to construct architecture work. Digital means make architecture work with irregular shape a reality. In the past, Gehry always thought that model and drawing were easier to express architecture visually than computer. However, with the deepening of inspiration degree of his work, traditional design methods can hardly bear the great pressure brought by fantastical notion about shape, causing Gehry to gradually practice and finally completely accept computer. In his work Disney Concert Hall, the external form of the main part of the whole building develops completely according to acoustic design result; the internal spatial scale of the room is adjusted according to the sound vibration time evaluated by digital technology, including the measurement of air duct curvature, change of luminous environment in one day and wind load analysis etc. However, Eisenman applied computer in a different way. He no longer gave the concept of "computer aided", but conducted architectural design directly on computer. They represent two different trends of using computer for design.

Digital virtual reality technology is a computer system that can create and manifest virtual world. The application of VR technology in the process of architectural design allows the design process to be visual and architects to fully experience advantages and disadvantages of the internal functional layout and external environmental design of buildings as if they are staying in the place to be constructed and helps architects to better verify the correctness and feasibility of design.

\subsection{Influence of Digital Technology on Architectural Design Thinking Model}

For a long time, graphical information is the main medium of design and expression of architectural space. It plays an irreplaceable role in the process of formation, analysis and professional expression of conception of building scheme. Professional technological means and tools of graphical information often influence design thinking. As a professional thinking model, the traditional graphical thinking mode makes the content object and professional design information of architectural design closely connected through a series of links such as drafting, model making and drawing formation and modification. Digital technology represented by computer aided design can transfer this process to virtual 3D digital world. This situation is called as "digital thinking". In the early stage of technological development, design thinking under digital technology does not support the rapid development of concept directly in the thinking process of designers. Therefore, they used to only accurately describe, refine and file concepts with complete development. Currently, digital technology has made substantive progress. Besides allowing architects to have more visual abstract thinking closer to the reality, more importantly, it can break through regular design rules and allow architects to get breakthrough and innovation in technology and find poetic shape pursuit. The conception of architectural space can 
have freedom and randomness like sculpture. Moreover, it may update design thinking and method and form architectural digital information model with overall integration, more dynamic participation and wide horizontal cooperation etc.

\section{$3 \quad$ Teaching Situation of Traditional Computer Aided Architectural Design Curriculum}

Currently, the teaching of computer aided architectural design curriculum is led mainly according to two different clues domestically. One is design expression, including 2D architectural drawing and 3D modeling, 3D architectural rendering and image processing, multi-media architectural expression and demonstration[1]. For example, architecture major of the College of Architecture and Urban Planning, Guangzhou University currently provides architectural CAD teaching mainly in two parts - basic theories of architectural CAD and CAD aided drawing and making of computer aided architectural design sketch. The other is design concept. For example, Southeast University attempted to establish architectural design model by using computer as the design tool, simulate the whole process of program conception in three steps - volumetric model, structural model and architectural model and realize collaborative design with internet as the communication platform. Through the analysis on the application of computer in architectural design by two avant-garde American architects Gehry and Eisenman, we clearly realize that the influence of computer on architectural design not only involves expression. University academic advisory committee also advocates that architectural CAD should take the clue of design concept. However, it is restricted by many factors in actual operation, such as the lack of easy-to-learn, easy-to-use and effective computer software technology and guidance of architectural CAD experts. Moreover, it is better to synchronize computer aided architectural design and architectural design curriculum. Such operation has a high difficulty of coordination. Therefore, teaching with design expression as the clue is more often used currently.

\section{How to Reform Architectural Design Teaching Mode So as to Give Full Play to Advantages of Architecture Major in Digital Times}

The author thinks that CAD teaching throughout architecture major should not stand on expression clue or conception clue because expression and conception should be basic qualities of architectural designers. Our teaching of architecture should be led by requirements of the market for architects with the clue of the process in which students accept and learn architectural design. Complete CAD teaching should contain three parts: part 1 includes brief introduction to the development history of architectural CAD technology, application situation, software and hardware system and main technologies; part 2 includes computer aided analysis in terms of architectural environment, shape, space and physical characteristics; part 3 is 2D, 3D 
and multi-media computer performance of design achievements. Currently, in terms of architectural CAD course arrangement in many universities, computer aided architectural design expression occupies the majority of class hours. Some universities even incorporate architectural CAD into design expression courses in teaching curriculum system planning. This obviously neglects the important role of basic theories of computer aided architectural design and computer aided architectural design concept in architecture major.

As a professional teacher of architectural graphing and architectural design curriculum, the author brings forward his own opinions on CAD course teaching of architecture according to his years of teaching experience. As the first part of architectural CAD, basic theories of architectural CAD and contents of drawing part can be explained in combination with descriptive geometry and computer part of shadow and perspective in freshman year so as to help students establish the elementary contour of this technology. In this part, we can be oriented at practicality and teach in combination with small architectural design in basic courses of architectural design in freshman year so as to arouse students' learning interest and improve the operability of architectural CAD technology. Previously, most of us thought that students majoring in architecture should not touch computer too early, which is adverse to the cultivation of students' early architectural accomplishment. The author thinks that, with the increasing development of computer today, if computer aided teaching is beneficial to the study of professional knowledge and training of professional skills and good for arousing students' learning enthusiasm and cultivating students' innovation ability, we should spare no effort to apply it. For the second part computer aided architectural design concept, we can gradually teach in stages and grades. For example, we can start from architectural design curriculum in sophomore year, conduct environmental simulation, spatial analysis, form conception and achievement expression in the conception process of program design with SketchUp software, use it as the computer tool of aided architectural design concept and teach ideological contents of computer architectural design concept. Architectural design curriculum in junior year can further involve "VR" technology, architectural environment and architectural program modification with software "Ecotect". Less class hours are provided for the last part - computer design sketch making course. Students should mainly study on their own and teachers explain key points and difficult points of this technology in class and guide students to complete course work. Through such series of course learning, students can comprehensively understand architectural CAD technology. This technology is no longer only a drawing tool, but it actually applied in each stage of design.

Architecture is an integrated discipline. The education of architecture major shows the superiority of systematic cultivation of students majoring in architecture in multiple aspects such as color sense, relationship of composition of proportions, streamline functional space organization design, style design, structural form selection, building construction, building materials and architectural history. Digital technology is only a tool used in architectural design, which is conducive to producing more excellent architectural design works, accelerating architectural design mapping and improving architects' sense of 3D space. However, it cannot replace 
architectural design of architecture major based on system theory. Today, with increasingly wider computer aided architectural design, some students think that free basic skill training is not indispensable. It seems that computer can accomplish all work completed by manpower previously, resulting in sharp decrease of students' on-hand expression ability. This becomes a universal phenomenon in the department of architecture of various universities. In fact, when technologies become more advanced, people should attach more importance to the improvement of their own quality and ability. Basic skills contain double meanings - graphic capability (ability of expression) and design ability. The cultivation of design ability mostly originates from the training process of the ability of expression. Therefore, proper use and correct understanding of computer technology will help students to learn architecture well more smoothly.

\section{Conclusion}

Though digital technology has been applied in architectural design for a short time, the change brought by it is very striking and it gradually becomes mature. Ranging from program design drawing and working drawing in the early stage to 3D modeling and image processing to animation and virtual reality and the establishment of architectural information model, its major function is not impairing architects' creative activity but freeing architects with creative talent from a lot of tedious and repetitive work through the superiority of digital technology and allowing them to have more energy to be engaged in architectural creation.

\section{References}

[1] Wang, G.: Digital Means and Virtual Reality Technology in Architectural Design Application and How to Promote Innovation and Development of Architectural Design. School of Architecture, Central Academy of Fine Arts, Beijing (2007)

[2] Yang, L.: Research on Digital Technology and Architectural Design Methods. Master's Thesis. Tongji University, Shanghai

[3] Yang, H.: Research on Non-linear Form Design Methods of Architecture. Master's Thesis. Tongji University, Shanghai

[4] Guo, L.: Analysis and Research on Digital Architectural Expression Art Based on 3D Computer Technology. Master's Thesis. Nanchang University, Jiangxi

[5] Zhang, L.: Architecture and Architectural Design in Information Era. Tsinghua University Press, Beijing (2000) 